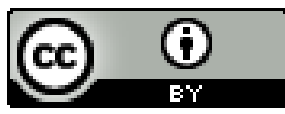

\title{
SOLIDÃO DA MULHER NEGRA: UMA REVISÃO DA LITERATURA
}

\author{
Táhcita Medrado Mizael ${ }^{1}$ \\ Universidade de São Paulo, Instituto de Psicologia, São Paulo, SP, Brasil. \\ Sarah Carolinne Vasconcelos Barrozo ${ }^{2}$ \\ Universidade Federal do Pará, Núcleo de Teoria e Pesquisa do Comportamento, \\ Belém, PA, Brasil. \\ Maria Helena Leite Hunziker ${ }^{3}$ \\ Universidade de São Paulo, Instituto de Psicologia, São Paulo, SP, Brasil.
}

\begin{abstract}
Resumo: Este trabalho revisou a literatura sobre a solidão da mulher negra, buscando entender os significados atribuídos a essa terminologia. Utilizaram-se as bases Portal de Periódicos CAPES, Banco de Teses e Dissertações da CAPES e plataforma BVS, e os descritores "solidão da mulher negra/preta" e "rejeição da mulher negra/preta". Foram selecionados e analisados oito trabalhos ao todo. Seis trabalhos focaram em mulheres negras adultas e em relacionamentos entre um homem e uma mulher. A solidão da mulher negra foi relacionada principalmente a falta de um parceiro, ao abandono parental e/ou do próprio parceiro e ao preterimento afetivo-sexual. O racismo é tido como o fator determinante dessa solidão. Variáveis relacionadas ao machismo também foram apontadas. Discute-se a importância de ampliar a discussão sobre o impacto da cultura na preferência afetivo-sexual.
\end{abstract}

Palavras-Chave: Solidão da Mulher Negra; Racismo; Machismo; Preferência AfetivoSexual; Negritude.

\section{BLACK WOMAN'S LONELINESS: A LITERATURE REVIEW}

\footnotetext{
${ }^{1}$ Psicóloga, mestra e doutora em Psicologia (UFSCar). Especialista em gênero e sexualidade (UERJ). Atualmente, é pesquisadora de pós-doutorado na Universidade de São Paulo (Bolsista FAPESP; Processo N. 2020/02548-7). E-mail: tahcitammizael@gmail.com ; ORCID: https://orcid.org/0000-0002-5543-1188

${ }^{2}$ Sarah Carolinne Vasconcelos Barrozo possui graduação em Psicologia pela Universidade Estadual do Piauí e mestrado em Análise Experimental do Comportamento pela Universidade Federal do Pará. E-mail: svasconcelospsi@gmail.com ; ORCID: https://orcid.org/0000-0003-3171-5722

${ }^{3}$ Licenciada, Bacharel e Psicóloga pela Pontifícia Universidade Católica de Campinas (1973 e 1974), Mestre, Doutora e Livre-Docente em Psicologia Experimental pela Universidade de São Paulo. Atualmente é professora sênior na Universidade de São Paulo. E-mail: hunziker@usp.br ; ORCID: https://orcid.org/0000-0003-0030-375X
} 
Abstract: This paper reviewed the literature on Black women's loneliness, seeking to understand the meanings expressed in this terminology. The databases Portal de Periódicos CAPES, Banco de Teses e Dissertações da CAPES and plataforma BVS were used, as well as the descriptors "Black woman's loneliness" and "Black woman's rejection". Eight publications were selected and analyzed. Six publications focused on adult Black women and in relationships between a man and a woman. The Black women's loneliness was mainly related to the lack of a partner, parental/own partner abandonment and sexual-affective neglect. Racism is seen as the determining factor in this loneliness. Variables related to sexism were also pointed out. The importance of broadening the discussion on the impact of culture on affective-sexual preference is discussed.

Keywords: Black Woman's Loneliness; Racism; Sexism; Affective-Sexual Preference; Blackness.

\section{SOLEDAD DE LA MUJER NEGRA: UNA REVISIÓN DE LA LITERATURA}

Resumen: Este artículo revisó la literatura sobre la soledad de las mujeres negras, buscando comprender los significados atribuidos a esta terminología. Se utilizó las bases de datos Portal de Periódicos CAPES, Banco de Teses e Dissertações da CAPES y plataforma $B V S$ así como los descriptores "soledad de la mujer negra" y "rechazo de la mujer negra". Se seleccionaron y analizaron ocho obras en total. Seis obras se centraron en mujeres negras adultas y en las relaciones entre un hombre y una mujer. La soledad de las mujeres negras se relacionó principalmente con la falta de pareja, el abandono de los padres o de la propia pareja y a la negligencia afectivo-sexual. El racismo se ve como el factor determinante de esta soledad. También se señalaron variables relacionadas con el machismo. Se discute la importancia de ampliar la discusión sobre el impacto de la cultura en la preferencia afectivo-sexual.

Palabras-clave: Soledad de la Mujer Negra; Racismo; Machismo; Preferencia AfectivoSexual; Negrura.

\section{LA SOLITUDE DE LA FEMME NOIRE: UNE REVISION DE LA LITTERATURE}

Résumé: Cet article a passé en revue la littérature sur la solitude de la femme noire, cherchant à comprendre les significations attribuées à cette terminologie. Le portail du journal CAPES, la base de données des thèses et mémoires du CAPES et la plateforme BVS ont été utilisés, ainsi que les descripteurs « solitude de la femme noire» et « rejet de la femme noire ». Huit œuvres au total ont été sélectionnées et analysées. Six œuvres se concentrent sur les femmes noires adultes et les relations entre un homme et une femme. La solitude de la femme noire était principalement liée à l'absence de partenaire, à l'abandon parental/ du propre partenaire et à la négligence affective-sexuelle. Le racisme est perçu comme le facteur déterminant de cette solitude. Des variables liées au machisme ont également été signalées. L'importance d'élargir la discussion sur l'impact de la culture sur la préférence affective-sexuelle est discutée.

Mots-clés: Solitude de la Femme Noire; Racisme; Machisme; Préférence AffectiveSexuelle; Négritude. 


\section{INTRODUÇÃO}

O racismo é um conjunto de práticas que pressupõe uma hierarquização de indivíduos com base em sua cor/raça ${ }^{4}$, levando a privilégios para a população branca e desvantagens para a população negra e outras populações não-brancas (e.g., ALMEIDA, 2019). Embora atinja toda a população negra - além de outras populações não-brancas, como a população indígena -, as pessoas negras afetadas pelo racismo não são "apenas" pessoas negras, ou seja, não são sujeitos que possuem apenas uma raça, mas trazem outros marcadores sociais, como uma classe social, uma religião, uma nacionalidade, um gênero etc., que, em articulação com a raça, podem levar a experiências distintas e bastante particulares. Podemos chamar de interseccionalidades uma área de estudo particularmente interessada na articulação entre dois ou mais marcadores sociais de um indivíduo ou grupo de indivíduos (e.g., AKOTIRENE, 2019; ALVES; MURTA; MOREIRA; 2021; CRENSHAW, 1989; NOGUEIRA, 2017). Nas palavras de Crenshaw (2002):

A interseccionalidade é uma conceituação do problema que busca capturar as consequências estruturais e dinâmicas da interação entre dois ou mais eixos de subordinação. Ela trata especificamente da forma pela qual o racismo, o patriarcalismo, a opressão de classe e outros sistemas discriminatórios criam desigualdades básicas que estruturam as posições relativas de mulheres, raças, etnias, classes e outras (CRENSHAW, 2002, p. 177).

Como dito anteriormente, a intersecção entre diferentes marcadores sociais pode gerar experiências de opressão. Sendo assim, neste trabalho, gostaríamos de nos voltar especialmente para a intersecção entre gênero e raça; mais especificamente, entre ser uma mulher negra em um mundo racista e patriarcal. Assim, é importante definir alguns termos. O patriarcado pode ser conceituado como uma estrutura de poder baseada em uma ideologia machista que hierarquiza os homens e mulheres, tendo primazia masculina e, por conta da desigualdade de poder existente entre os sexos, deixa as mulheres em posição inferior aos homens em todas as esferas da convivência humana (SAFFIOTI, 2004/2015).

\footnotetext{
${ }^{4}$ Em todo o trabalho, o conceito de raça utilizado é o seu sentido sociológico, ou seja, uma categoria de exclusão e dominação (MUNANGA, 2004), baseada em atributos físicos e/ou aspectos culturais de determinado grupo.
} 
Gênero pode ser conceituado como um "elemento constitutivo das relações sociais baseadas nas diferenças percebidas entre os sexos" e "uma forma primária de dar significado às relações de poder" (SCOTT, 1995, p. 86). Essa conceituação explicita o caráter socialmente construído do gênero e reconhece que o gênero é uma das formas pelas quais o poder se manifesta (sendo, geralmente, a subordinação de um sexo pelo outro). Como podemos então pensar a articulação do gênero feminino com a raça negra?

\section{Mulher negra: Algumas estatísticas}

De acordo com o dossiê "Mulheres negras e violência doméstica: Decodificando os números" (CARNEIRO, 2017), existem mais de 53 milhões de mulheres negras no Brasil. Apesar de constituírem, aproximadamente, um quarto da população brasileira, as mulheres negras se encontram na base em diversos indicadores sociais. Segundo a Síntese dos Indicadores Sociais publicada pelo IBGE (2018), dos 26,5\% de brasileiros vivendo abaixo da linha da pobreza, a maioria deles $(34,8 \%)$ são mulheres negras (pretas ou pardas $)^{5}$. Esse público também é maioria no que diz respeito à restrição de acesso à serviços básicos como proteção social e condições dignas de moradia (IBGE, 2018). Além disso, as mulheres negras constituem as principais vítimas de tráfico de mulheres, homicídios e feminicídios (IPEA, 2019).

Mesmo ganhando aproximadamente metade da remuneração recebida por mulheres brancas, as mulheres negras são chefes em mais da metade das famílias brasileiras (CARNEIRO, 2017). São também o grupo mais pobre e o que mais exerce trabalhos mal remunerados, como o trabalho doméstico remunerado (WENTZEL, 2018). É importante ressaltar que o termo que melhor descreve essas disparidades é o racismo (e.g., CARONE \& BENTO, 2014; HASENBALG; SILVA, 1988; ORGANIZAÇÃO DAS NAÇÕES UNIDAS, 2018; TELLES, 2003). Isto é, essas disparidades são consequências da vida em uma sociedade racista.

\section{Racismo e suas consequências para as mulheres negras}

\footnotetext{
${ }^{5} \mathrm{O}$ restante dessa população é composto por $34,1 \%$ de homens negros, $16,7 \%$ de homens brancos e $16,2 \%$ de mulheres brancas.
} 
Além das consequências apontadas anteriormente, a hierarquização dos indivíduos tendo como base a cor/raça teve inúmeros outros impactos para a população negra. Fazendo um brevíssimo histórico, registros apontam que aproximadamente 3.500.000 indivíduos escravizados vieram para o Brasil. Em 13 de maio de 1888, com a promulgação da Lei Áurea, aproximadamente 700 mil escravizados se tornaram "livres". Entretanto, essa liberdade veio sem nenhum tipo de reparação pelos séculos nos quais a população negra foi escravizada, sem nenhum tipo de condição para facilitar a transição de uma vida escravizada para uma vida independente, ou seja, sem nenhum tipo de recurso para construir ou comprar uma casa ou ter qualquer tipo de bem, e com a exoneração das responsabilidades dos senhores, do Estado e da Igreja, como consequência, estabeleceu-se o que pode ser chamado de escravidão em liberdade (e.g., NASCIMENTO, 2016).

Com a abolição, havia um grande "problema" na nação brasileira, que consistia em como lidar com a "mancha negra" existente no país. Diversas estratégias foram utilizadas para eliminar a população negra, como instituir o processo de miscigenação como algo positivo (mito da democracia racial), com o objetivo de branquear a população; a criação de uma política imigratória facilitada para europeus; a manipulação dos dados censitários (com a não coleta de dados sobre cor/raça em alguns anos, omitindo, assim, o aumento ou manutenção da população negra no país); e a eliminação da população afrodescendente, pela Lei da Vadiagem $(1941)^{6}$, pela violência policial e por diversos outros meios (NASCIMENTO, 2016; GUIMARÃES, 2001; SCHWARCZ, 1993; 2012).

Durante todo o tempo em que durou o processo de escravização, as mulheres negras frequentemente eram estupradas pelos senhores, os quais utilizavam o fenótipo das mulheres negras para justificar suas ações. Com essa desumanização/fetichização, até hoje as mulheres negras sofrem com comentários sobre seus corpos, considerados demasiadamente sexuais (BUENO, 2020; COLLINS, 2000; DAVIS, 1981/1983). Essas concepções reverberam até hoje na sociedade, e isso pode ser visto em comentários do tipo "branca para casar, mulata para transar, e preta para trabalhar". Assim, percebe-se

\footnotetext{
${ }^{6}$ Prevista no Art. 59 do Decreto-Lei no $3.688 / 41$, com pena variando entre quinze e três meses de prisão, a Lei da Vadiagem considera crime "entregar-se alguém habitualmente à ociosidade, sendo válido para o trabalho, sem ter renda que lhe assegure meios bastantes de subsistência, ou prover à própria subsistência mediante ocupação ilícita" (BRASIL, 1941).
} 
como a articulação de gênero e raça leva a experiências de vida bastantes distintas para as mulheres negras e brancas.

Recentemente, discussões que têm colocado as mulheres negras como foco de estudos e de protagonismo têm surgido em ambientes acadêmicos e não acadêmicos (como blogs, vídeos e podcasts). Um dos temas discutidos nesses espaços tem sido a solidão da mulher negra. Tal fenômeno aponta para o fato de que a experiência de solidão das mulheres negras é diferente da solidão que pode existir entre mulheres brancas, pois, embora ambas sofram os efeitos do machismo, as mulheres brancas não sofrem racismo. Nesse sentido, esse fenômeno tem sido considerado uma das consequências de uma sociedade racista e machista, ou seja, da intersecção entre marcadores sociais de gênero e raça apresentada anteriormente.

Embora, em vários desses contextos, essas discussões tendem a ser sobre a solidão afetivo-sexual dessas mulheres (e.g., SOUZA, 2008), é possível ver discussões sobre outros âmbitos de solidão, como, por exemplo, ser a única mulher negra em uma empresa ou sala de aula, ser uma criança negra que é rejeitada pelas colegas brancas, e ter dificuldade em se sentir representada nas grandes mídias (e.g., BARBOSA; SOUZA, 2018; XONGANI, 2018). Buscando um melhor entendimento sobre as definições do fenômeno descrito como solidão da mulher negra, o objetivo deste trabalho foi revisar a literatura em língua portuguesa sobre o tema, a fim de identificar os possíveis significados atribuídos a essa terminologia e discutir algumas possíveis causas dessa solidão. Ao final, também será discutido brevemente alguns impactos dessa solidão na vida das mulheres negras brasileiras. $\mathrm{O}$ interesse por esse tema se dá a partir da contatação, pela primeira autora, uma mulher negra, de que este fenômeno parece impactar significativamente a vida de mulheres negras. Espera-se que o melhor entendimento deste fenômeno possa auxiliar nos processos de psicoterapia e seja incorporado nos cursos de Psicologia, área na qual as autoras estão inseridas.

\section{MÉTODO}

As buscas foram feitas no Portal de Periódicos CAPES, no Banco de Teses e Dissertações da CAPES e na plataforma BVS. Os trabalhos selecionados deveriam ter como foco o fenômeno descrito como "solidão da mulher negra" e serem escritos em 
língua portuguesa. Trabalhos que abordaram esse fenômeno marginalmente não foram selecionados, assim como capítulos de livro, trabalhos de conclusão de curso, editoriais, e outros materiais que não constituíam artigo, tese, dissertação ou trabalho publicado em anais de eventos.

As palavras-chave utilizadas foram "solidão da mulher negra", "solidão da mulher preta", "rejeição da mulher negra" e "rejeição da mulher preta". As buscas foram feitas em setembro de 2020. Não foi delimitado um período de tempo para a escolha dos trabalhos, ou seja, trabalhos publicados desde o primeiro ano de existência das bases de dados poderiam aparecer na busca. Inicialmente, foram encontrados seis trabalhos no Portal de Periódicos CAPES, um no Banco de Teses e Dissertações CAPES, e um no BVS, totalizando oito. Dos oito trabalhos, seis foram descartados por não se encaixarem nos critérios de inclusão, restando apenas dois trabalhos (CARRERA; CARVALHO, 2019, e SOUZA, 2008). Como o número de resultados foi muito baixo e as autoras tinham conhecimento de outros trabalhos que não apareceram na busca, foi feita uma busca manual de trabalhos no Google, utilizando o descritor "solidão da mulher negra". Nessa busca, outros seis trabalhos foram encontrados. Desse modo, esse estudo revisou oito trabalhos publicados em português, cujo foco de discussão foi o fenômeno descrito como solidão da mulher negra.

\section{RESULTADOS}

A dissertação de Souza (2008) teve como foco as temáticas de solidão e afeto de mulheres negras, ainda pouco discutidas nos trabalhos sobre questões raciais, por meio de uma observação de casais, uso de questionário e grupo focal. Foi realizada uma análise observacional da frequência e proporção de casais intra e interraciais em bairros de classe média, bairros centrais e bairros da periferia da cidade de São Paulo, com foco para o número de casais formados por homem negro e mulher branca e/ou mulher negra e homem branco. Após a observação de 973 casais interraciais, obteve-se que a proporção de casais formados por um homem negro e uma mulher branca era de $77 \%$, contra $22 \%$ de casais formados por uma mulher negra e um homem branco ${ }^{7}$.

\footnotetext{
${ }^{7} \mathrm{O} 1 \%$ restante era constituído por casais formados por uma pessoa negra e a outra amarela (e.g., homem negro e mulher de raça amarela).
} 
Um questionário foi aplicado em 62 mulheres negras com até 58 anos de idade. As questões foram relacionadas a identidade étnico-racial, ao significado da solidão e da felicidade, e sobre a escolha de parceiros afetivo-sexuais em função da raça. Cinquenta e sete por cento das mulheres declararam estar em um bom relacionamento amoroso, $16 \%$ estavam insatisfeitas, e 27\% declararam não ter vida amorosa. Em conjunto, $47 \%$ das mulheres se declararam solitárias sempre ou às vezes (34\% sempre e 13\% às vezes), e de acordo com a maioria das entrevistadas, os homens negros preferem as mulheres brancas. Inclusive, é interessante ressaltar que os dados da análise observacional reforçam essa impressão das participantes.

Esses dados foram utilizados para definir temas para um grupo focal, constituído por onze mulheres negras, com idades entre 30 e 65 anos (idade média $=50$ anos). Os critérios para participação no grupo focal eram ser mulher negra e participar de alguma atividade ocupacional, de militância ou educacional. A maioria delas tinha ensino superior, já havia sido ou estava casada, e todas participavam de movimentos sociais. Em nenhum momento houve a menção da orientação sexual das participantes, mas os relatos foram sobre relacionamentos entre um homem e uma mulher. O objetivo do grupo focal foi investigar os sentidos que as mulheres davam para a solidão e se havia uma relação entre o sentimento de solidão e o preterimento afetivo por homens negros. Os resultados mostraram que existe uma percepção, por essas mulheres, de que os homens negros preferem mulheres brancas, por serem escolhas vantajosas no sentido de obter maior status social, por exemplo, e também por conta dos efeitos do racismo, o que levaria à percepção de que as mulheres negras seriam a última opção para um relacionamento. Os estereótipos sexuais referentes às mulheres negras, outro legado do racismo, também apareceram como justificativas para a preferência dos homens negros pelas mulheres brancas para o casamento e relações afetivo-sexuais mais estáveis ${ }^{8}$, enquanto as mulheres negras serviriam para o aprendizado da sexualidade por esses homens e para encontros casuais, onde a mulher negra seria utilizada como um objeto, visando a obtenção de prazer sexual e, depois, descartada.

O trabalho de Ana Cláudia Pacheco (2013) tinha como perguntas de pesquisa

\footnotetext{
${ }^{8}$ Segundo dados do Censo Demográfico sobre Nupcialidade, fecundidade e migração (IBGE, 2010a), em relação a seletividade matrimonial, homens pretos tenderam a escolher mulheres pretas em menor percentual $(39,9 \%)$ do que mulheres pretas em relação a homens do mesmo grupo (50,3\%).
} 
como gênero, raça e outros marcadores sociais operam nas trajetórias sociais e nas escolhas afetivas das mulheres negras selecionadas? Como as mulheres negras selecionadas pensam sobre as experiências da solidão?" (PACHECO, 2013, p. 45).

Para tanto, 25 mulheres negras, moradoras da cidade de Salvador (BA) e sem parceiros fixos, ou seja, sem união estável no momento da pesquisa, foram entrevistadas pela autora. Doze eram ativistas, e 13, não-ativistas. As mulheres trabalhavam em diferentes segmentos, como empregada doméstica, auditora fiscal, fisioterapeuta, autônomas etc. Dentre as ativistas, a maioria estava na faixa de idade de 35 a 50 anos de idade.

As comunalidades, entre as mulheres ativistas, para as razões de estarem sozinhas, apareceram: 1) o relato da preferência, pelos homens negros, ativistas ou não, de mulheres

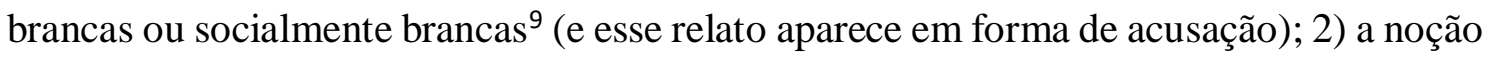
de que as "militantes assustam" os homens, seja por não se enquadrarem no estereótipo de gênero da mulher que 'lava, passa e cuida do marido o tempo inteiro', seja pelo interesse dos homens negros militantes nessas mulheres somente para relações casuais (sexo), seja pela espécie de "masculinização" que ocorre com as mulheres ativistas que, ao se engajarem em posições de poder (tradicionalmente masculinas), são vistas como menos femininas, ou pela preferência por mulheres consideradas "ingênuas" ou "despolitizadas"; e 3) a poligamia negra masculina, ou seja, o fato desses homens serem "mulherengos", traírem suas namoradas/esposas, inclusive por meio de relações extraconjugais de longa duração.

Entre as mulheres não ativistas, as razões dadas pela ausência de parceiros fixos/instabilidade nos relacionamentos afetivo-sexuais foram relacionadas: 1) a noção de que homens negros são poligâmicos e não possuem responsabilidade paterna, especialmente para as não-ativistas da camada popular (citando, muitas vezes, o abandono do próprio pai por interesse em outras mulheres, ou por já possuir um relacionamento extraconjugal); 2) conflitos relacionando raça, gênero e classe: entre as mulheres negras que obtiveram ascensão social, a dificuldade de encontrar e manter parceiros negros estava relacionada, de acordo com seus relatos, com a figura do "gigolô" ou do "homem encostado", na qual os homens negros eram mais pobres que suas parceiras

\footnotetext{
${ }^{9}$ Não há, no texto, uma definição do que seriam "mulheres socialmente brancas". A interpretação que fizemos foi de que seriam negras de pele clara, descritas, às vezes, como brancas, e/ou confrontadas quando se classificam como negras ("você não é tão preta assim").
} 
e estas o sustentavam. No caso dos homens brancos, especialmente se forem estrangeiros, as mulheres relataram que tendem a ser vistas como "a negra prostituta que quer se dar bem com o gringo", ou seja, os constrangimentos sociais são relatados como as razões pelas quais relacionamentos exogâmicos com esses homens não foram duráveis. Entre as ativistas, havia ainda a pressão do movimento negro, julgando o relacionamento entre uma mulher negra e um homem branco.

Dentre os pontos em comum entre as mulheres negras ativistas e não-ativistas, está a origem familiar humilde, com os pais exercendo trabalhos com baixa remuneração; entre as mulheres da família, era comum desempenharem funções como empregada doméstica ou trabalhar no plantio e colheita. Os pais desempenhavam serviços "braçais", como trabalhador rural, motorista ou operário da construção civil. A religião também apareceu como uma comunalidade, embora em menor expressão que a origem familiar pobre. A religião foi vista como uma visão de mundo, uma forma de interpretar seus relacionamentos, uma maneira de afirmar a identidade negra, um espaço de interação social, uma maneira de "burlar" a solidão, entre outros significados.

Dentre as diferenças das mulheres negras ativistas e não-ativistas, embora a educação fosse valorizada em ambos os grupos, as trabalhadoras domésticas tiveram menos oportunidades de educação, necessitando do serviço doméstico como meio de subsistência. Para as mulheres que ascenderam socialmente, a educação foi um fatorchave para essa ascensão. De acordo com Pacheco (2013), as participantes ativistas utilizavam frequentemente "nós" ou "elas" para se referir às mulheres negras. Entre as não-ativistas, foi mais comum o pronome pessoal “eu”. Para Pacheco (2013), esse uso da terceira pessoa é uma maneira de demonstrar a percepção do aspecto político das relações sociais e afetivas, além do pertencimento étnico-racial destas mulheres. De fato, de acordo com a análise da autora, as mulheres ativistas relacionaram gênero, raça, classe e geração com política, enquanto as mulheres não-ativistas não acionaram a categoria de "política" em seus relatos.

A pesquisa de Júlia Gregório (2017) teve como objetivo discorrer sobre a solidão da mulher negra encarcerada. A autora traz que $68 \%$ das mulheres encarceradas são negras, e parte de uma concepção ampla de solidão (sentimento de solidão advindo do preterimento afetivo-sexual, do abandono paterno, do afastamento parental), discorrendo 
sobre o impacto de uma sociedade racista no sentimento de solidão. Nas palavras da autora:

Estudos apontam o alto índice de preterimento da mulher negra frente a mulher branca pelos homens negros, no âmbito afetivo-sexual/conjugal, o que acarreta o sentimento de solidão e humilhação às mulheres negras. Porém, a solidão da mulher negra antecede sua vida adulta e extrapola suas relações amorosas. A Solidão da Mulher Negra, vem desde a infância - em uma família desestruturada pelo machismo validado por uma sociedade patriarcal e o racismo validado por um Estado genocida -, perpassa a fase escolar - com o isolamento para evitar humilhações racistas por parte de colegas e professores -, atinge a adolescência - na construção solitária de uma identidade "aceitável" - e alcança a vida adulta - nas relações amorosas, na vida profissional, nos serviços de atenção à saúde, na criação dos filhos que o Estado não matou não prendeu (GREGÓRIO, 2017, p. 5).

O método da pesquisa consistiu em comparar as leis e regulamentações a respeito da maternidade em situação de prisão, com dados de levantamentos publicados pelo INFOPEN ou outras entidades. Embora a Lei n. 11.942/09 assegure às mães reclusas e seus filhos recém-nascidos condições mínimas de assistência para que exerçam a maternidade, e a Lei n. 12.962/14 regulamente o convívio entre os genitores em situação de prisão e seus filhos, a autora comenta que, de acordo com um levantamento feito pelo INFOPEN e divulgado em 2014, apenas 34\% dos presídios femininos possuía cela ou dormitório adequado para gestantes. Um número expressivamente menor de espaços adequados para gestantes estava presente nos estabelecimentos mistos (6\%). Somente $32 \%$ das unidades femininas possuíam centro de referência materno-infantil ou berçário, ao passo que apenas $3 \%$ das unidades mistas tinham esses espaços. Por fim, somente 5\% das unidades femininas possuíam creche, enquanto que nenhuma creche foi instalada nos estabelecimentos mistos. Esse tipo de situação, extremamente insalubre, faz com que muitas mulheres prefiram que seus filhos fiquem com outros membros da família ou até sejam adotados.

Ainda em relação às mães com seus filhos, mais de $70 \%$ das mulheres presas declarem não receber visita dos filhos. Segundo a autora, isso acontece devido à falta de recursos financeiros, por parte dos familiares, que dificulta levar os filhos para as visitas; assim como a vergonha por parte das mães, de que seus filhos as vejam presas, entre outras razões. Com relação as visitas íntimas, a autora traz dados que mostram que menos de $10 \%$ das mulheres presas recebem visitas íntimas, apesar de mais de $70 \%$ das instituições penais permitirem esse tipo de visita. A autora conclui que essas mulheres, 
em sua maioria negras, são abandonadas pelo Estado, pela ausência de políticas públicas específicas, assim como pelas próprias familiares e companheiros.

A pesquisa de Lorena Ferreira (2018) teve como objetivo analisar a peça "Engravidei, pari cavalos e aprendi a voar sem asas", de Cidinha da Silva, refletindo sobre afetividade e solidão da mulher negra. Como aporte teórico, foram utilizados principalmente os trabalhos de Pacheco (2003) e de Souza (2008). A peça conta com seis personagens negras: a DJ, a Puta, a Princesa de Carnaval, a Dona do Salão de Cabeleireiros, a Moradora de Rua e a Alcóolatra.

Ferreira (2018) comenta que Cidinha da Silva construiu a peça com base em 55 entrevistas realizadas por mulheres negras de diversos locais: em situação carcerária, universitárias, em situação de rua, estrangeiras, sambistas, entre outras. Todas as personagens passam por situações de solidão (estarem sozinhas), seja por abandono parental e/ou morte da mãe, pela instabilidade nos relacionamentos afetivo-sexuais, abandono pelo parceiro etc.

São discutidas questões como estratégias de embranquecimento (a dona de salão de cabeleireiros tem uma mãe branca, que alisava seu cabelo quando ela era criança e dizia que ela era "quase branca"); racismo (a Moradora de Rua, após sofrer um estupro, relata que o homem que a violentou disse que "só precisava fazê com força da primeira vez, porque ele ficava doido demais com o cheiro de cadela preta largada na rua") e machismo (reclamar das roupas que a dona do salão de cabeleireiros usa); violência de gênero (o marido da puta a espancava e a alcóolatra sofria violência física pelo pai); violência obstétrica (a alcóolatra relata: "me cortaram até o $\mathrm{cu}$, me costuraram sem anestesia"), entre outros. Ou seja, são situações aversivas frequentes na vida de muitas mulheres negras. Apesar de não definir o que está sendo chamado de "solidão da mulher negra", Ferreira (2018) relata que a solidão identificada nessa peça não se refere apenas a solidão afetivo-sexual, mas também a ausência de uma família, ao abandono pelo pai e/ou pelo parceiro, à rejeição afetiva, entre outros tipos de solidão.

Em sua dissertação de mestrado, Eliane Fernandes (2018) procurou compreender quais elementos relacionados ao racismo se mostram presentes nas vivências amorosas de mulheres negras. Com fundamentação teórica na psicologia social, Fernandes (2018) entrevistou 10 mulheres negras, todas com idade acima de 18 anos. Dentre as participantes, nove se identificaram como mulheres cisgêneros e uma como travesti. A 
entrevista semiestruturada, instrumento de coleta dos dados, foi gravada em áudio e realizada individualmente. Seguindo o método qualitativo de coleta e análise de dados, Fernandes (2018) destrinchou os resultados em quatro tópicos passíveis de análise: 1) a (possível) solidão afetiva da mulher negra; 2) a busca de mulheres negras pelo amor em relacionamentos afro centrados; 3) os esforços das mulheres negras para se encaixar nos padrões de brancura; e 4) a interlocução entre raça, identidade e racismo, e seus efeitos psicossociais.

No primeiro tópico, nomeado de "Solteira sim, sozinha nunca, objetificada sempre: a solidão afetiva da mulher negra”, Fernandes (2018) traz que as relações vivenciadas por mulheres negras são permeadas pelo estereótipo da mulata, a mulher fogosa sempre disponível (apenas) para o sexo. O ato sexual então funciona como um caminho primeiro para a construção das relações afetivas. Desse caminho, desembocam outros dois: a dinâmica sexo-relação casual-lugar de amante (ou mulata - relatada por nove das 10 participantes) e, no extremo oposto, a negação de relações sexuais para escapar do estereótipo de mulata, seguida pela experiência da solidão.

Como alternativa para driblar a experiência de solidão, encontra-se a busca por relacionamentos amorosos afro centrados, pois conjetura-se que pessoas negras seriam capazes de entender as opressões e as dificuldades vivenciadas por essas mulheres. Anteriormente a essa procura, foi presente nos relatos o frequente sentimento de não serem assumidas pelos parceiros, ou seja, de se sentirem sexualmente desejadas, mas não amadas. Contudo, esse trajeto de busca também é marcado por experiências de solidão, visto que homens negros, especialmente em ascensão econômica, também tendem a preferir relacionamentos com mulheres brancas.

Um outro braço do racismo que afeta diretamente suas vivências amorosas é o desejo pela brancura. Uma das consequências do racismo científico, representado pela política eugenista de branqueamento racial por meio da mestiçagem, foi a "fragmentação da população negra numa escala valorativa de cor" (FERNANDES, 2018, p. 78). Nesse sentido, fomos ensinados a tomar como modelo ideal padrões de brancura (traços europeus, cabelo liso e claro, olhos e peles também claras, magreza etc.). Os esforços das mulheres negras para se encaixar nos padrões de brancura são evidenciados através dos relatos sobre alisamento e tintura dos cabelos, isto é, todas as participantes passaram por embranquecimento estético (FERNANDES, 2018). 
Fernandes (2018) também salienta que a formação da identidade das mulheres negras - de qualquer indivíduo, na verdade - acontece através da relação indivíduosociedade, como defendido por vários teóricos e teóricas (e.g., BOCK, 1999; ERIKSON, 1972; SKINNER, 1953; 1976). Como dois lados diferentes de uma mesma moeda, foram identificados tanto efeitos negativos quanto efeitos positivos relacionados à formação de tal identidade. A relação entre a vivência de mulheres negras e a sociedade é permeada fortemente pelo racismo. Assim, um autoconceito negativo, a desvalorização sobre si e implicações negativas na saúde mental da população negra apareceram como alguns dos impactos psicossociais do racismo. Além disso, ao se afirmarem como negras, assumindo também as características da negritude (e.g. usar o cabelo ao natural), as participantes notaram a diminuição das relações afetivas. Em contrapartida, os efeitos positivos estavam associados ao fato de que o reconhecimento como mulheres negras traz consigo o resgate da própria história e do amor-próprio (FERNANDES, 2018). Com isso, a autora nos instiga ao dizer que "é necessário borrar as cores do amor para que ele seja possível" (FERNANDES, 2018, p. 94).

O estudo de Barbosa e Souza (2018) teve como objetivo investigar como meninas negras protagonistas de desenhos infantis são representadas em programas de TV paga brasileiros. Para isso, foram analisadas as grades de programação de 10 canais: Boomerang, Cartoon, Discovery Kids, Disney Channel, Disney Jr, Disney XD, Gloob, Nick, Nick Jr., e Rá tim bum. Seis personagens foram encontradas: Abigail, também conhecida como "Número 5" (KND - A turma do bairro); Doutora (Doutora Brinquedos); Lili (Meu amigãozão); Nella (Nella, uma princesa corajosa); Manu (SOS Fada Manu); e Twinkle (Os heróis da cidade).

Das 193 animações existentes, os seis programas constituem apenas 3\% das animações. A partir de uma análise qualitativa e quantitativa, as autoras escolheram aleatoriamente 10 episódios de cada animação para traçar um perfil de cada menina protagonista. Apesar de serem todas negras, a maioria das personagens possui pele clara (66,7\% das personagens). Apresentam também cabelos longos (50\%) e crespos ou enrolados ( $50 \%$ das personagens), e são de classe média ou alta (A ou B; 83,4\%). Somente uma personagem é da classe C (Manu, da única animação brasileira encontrada).

As autoras discutem o quanto esses programas consumidos por crianças negras brasileiras são diferentes da realidade em que elas vivem. Por exemplo, quatro das seis 
protagonistas possui um quarto somente para elas. Além disso, praticamente não há referências às culturas negras nos desenhos, com predomínio de signos de feminilidade (e.g., laços, unicórnios, corações, flores) para quatro das seis personagens (Doutora, Lili, Nella e Twinkle).

Nas interações sociais, as meninas se relacionam predominantemente com personagens não-negros (83,3\% dos casos), e embora a família constituía essa "ilha negra", isto é, o único lugar onde as meninas conversam com outras pessoas negras, a temática da raça não é evocada nesses diálogos. De acordo com as autoras:

Todo o cenário examinado, tanto em termos quantitativos quanto qualitativos, aponta que a cor está na tela, mas a raça não. [...]. Ou seja, no contexto dos episódios das animações, as imagens de meninas negras protagonistas não reivindicam elementos da negritude para além dos atributos corporais. A inclusão se encerra nos cabelos mais encaracolados e numa pele mais escura, pois a raça não importa para as narrativas desses desenhos. Em nenhum dos episódios das animações há alguma menção a temas como preconceito, ancestralidade, racismo, interseccionalidade, classe, representatividade, sororidade. A impressão que fica é a de que as meninas poderiam ter qualquer cor. Apenas calhou de serem negras (BARBOSA; SOUZA, 2018, pp. 86-87).

Boa parte dos canais analisados são famosos por comercializarem produtos como fantasias, aplicativos de celulares, jogos e acessórios de maneira geral. Entretanto, quantas meninas negras poderiam comprar tais produtos, que costumam ser caros? Como dizem as autoras:

Qual a efetividade desse modelo de representação quando não assume um compromisso mais profundo com questões que envolvem a raça (e o racismo)? Essa representatividade tem valor político ou é apenas uma forma de suprir demandas mercadológicas de inclusão das minorias que hoje tensionam de forma acirrada as representações e o consumo de produtos midiáticos? Quais mudanças efetivas essas representações podem trazer para a vida das meninas que as consomem? (BARBOSA; SOUZA, 2018, p. 87).

Nesse sentido, os desenhos representam uma era "pós-racial", na qual a raça não seria um critério para discriminar os indivíduos. Apesar de a mídia também ter um papel na representação de como a vida "poderia ser", as autoras argumentam que, devido a representatividade ser tão limitada (como pode ser visto pelo número de protagonistas negras nos desenhos),

os desenhos animados projetam duplamente, a nosso ver, solidão para as meninas negras. Afinal, a ilha de negritude que povoa as animações é a única coisa 
compatível com a realidade dessas meninas... Diegeticamente, essas meninas negras estão sós. Não convivem com outros sujeitos negros, não constroem afetos ou criam laços com outras crianças negras (BARBOSA; SOUZA, 2018, p. 91).

A pesquisa de Carrera e Carvalho (2019) teve como objetivo identificar como pessoas negras, no contexto da família, são representadas em bancos de imagens digitais. Como as autoras explicitam:

mais do que expor a falta de representatividade destes espaços, este trabalho se propõe a questionar quais os processos de definição de relevância que estabelecem algumas fotografias e ilustrações como mais ou menos pertinentes na busca por determinado grupo social em bancos de imagens digitais (CARRERA; CARVALHO, 2019, p. 6).

Para conceitualizar "solidão da mulher negra", as autoras utilizam o conceito de Norbert Elias, que não é específico às mulheres (negras ou não), assim como dados que indicam que as mulheres negras têm sido preteridas em relações afetivo-sexuais tanto por parceiros homens brancos, como negros. Nas palavras das autoras:

De acordo com Elias (1985) o conceito de solidão, em diversas situações, está relacionado não apenas a pessoas que por motivos específicos, são deixadas por outras pessoas, mas também à vivência de pessoas que não fazem diferença e não possuem significado afetivo em meio a pessoas que estão ao seu redor. Desde as décadas mais recentes do século XX, a miscigenação na sociedade brasileira tem sido desenvolvida em sua maioria pela preferência dos homens negros por parceiras não negras no campo afetivo-sexual (AZEVEDO, 1955, apud CARRERA; CARVALHO, 2019, p. 11).

Assim, as autoras partem de uma concepção de solidão com múltiplos sentidos (pessoa que foi abandonada por outra, pessoa sem laços afetivos com outras que estão por perto) e chegam nos dados sobre mulheres sós, sem parceiros homens, declarando que tal solidão é fruto de ideias racistas e machistas, que colocam a mulher negra como um instrumento servil sem mente, cuja única função é subserviente, seja no sentido sexual, seja no sentido do trabalho doméstico. Ainda, são vistas como menos atraentes por estarem longe dos ideais de feminilidade brancos.

Nesse sentido, as autoras constataram que os algoritmos utilizados nos bancos de imagens digitais também sejam uma forma de priorizar representações de mulheres negras como uma "mulher sozinha disponível para exploração laboral e sexual" 
(CARRERA; CARVALHO, 2019, p. 13). Para investigar essas hipóteses, as autoras utilizaram três bancos de imagens digitais: Getty Images, Stock Photos, e Shutterstock.

O procedimento consistiu em digitar as palavras-chave buscadas ("Black family" e "White family"), e analisar os resultados obtidos nas três primeiras páginas, classificadas por relevância (maior para menor). No total, 1592 imagens foram analisadas. Como forma de "controle", também foram buscados os resultados para a palavra "family", sem a especificação da raça. Novecentas e vinte imagens foram obtidas a partir dessa palavra-chave.

Entraram na categoria "mulheres sozinhas" fotos de mulheres que não tinham nenhuma pessoa do gênero masculino, ou seja, o dado sobre o preterimento afetivo e a solidão da mulher negra foi justamente a porcentagem de imagens de mulheres negras sem a presença de uma figura masculina ao lado delas, em comparação com a quantidade de mulheres brancas sem homens ao lado.

Os resultados mostraram que, das 792 imagens obtidas com as palavras "Black family", 14,01\% eram mulheres negras sozinhas. Em comparação, das 800 imagens que apareceram com a palavra-chave "White family", 9,25\% eram de mulheres brancas sozinhas. Nos três bancos de imagens, uma proporção maior de mulheres negras aparecia sozinha, em comparação com mulheres brancas.

Outro resultado interessante nessa pesquisa se referiu ao que foi obtido com a palavra-chave "family", sem a especificação racial: nessa condição, de acordo com as autoras, os algoritmos “entendem” que a pesquisa é neutra. Das 920 imagens encontradas, $58,04 \%$ eram de famílias brancas, enquanto que 6,3\% eram negras, e outros 6,19\% eram famílias de outras raças ou interraciais (as demais imagens, 29,47\%, eram de crianças ou adultos sozinhos, objetos, paisagens ou outras imagens que não entravam em nenhuma dessas três categorias). Como podemos ver pelos resultados, no entanto, é possível perceber como o branco não é considerado racializado, ou seja, como o branco é visto como a neutralidade.

Por fim, Eva Dayane Goés (2019) também se debruçou sobre o estudo da solidão vivenciada por mulheres negras, no caso, vítimas de violência doméstica. Ademais, a autora analisou a rede de enfrentamento à violência contra a mulher na cidade de Itabuna (BA) e de que forma essa rede cumpre seus propósitos de prevenção, combate e enfrentamento à violência doméstica. Utilizando-se das metodologias de análise de 
pesquisas qualitativas, Goés (2019) não apenas buscou descrever o fenômeno da solidão das mulheres negras vítimas de violência doméstica, mas também compreender sua simbologia através da contextualização dos papéis dos sujeitos estudados. Para tanto, a pesquisadora utilizou-se de entrevistas semiestruturadas com a) quatro mulheres negras vítimas de violência doméstica residentes em Itabuna (BA); e b) gestoras/servidoras (vereadora, delegada, tenente, promotores) da rede de enfrentamento a violência doméstica. A entrevista semiestruturada com as mulheres negras vítimas de violência continha tópicos como: dados sobre estado civil/afetivo atual, histórico de violência doméstica, perguntas sobre a vida afetiva (solidão, racismo, machismo, rede de apoio), história de vida etc. Já a entrevista semiestruturada com as gestoras e servidoras abordou tópicos relacionados a análise da qualidade da rede de enfrentamento.

À medida que discorre em detalhes os relatos das mulheres vítimas de violência entrevistadas, Goés (2019) faz um paralelo entre o que foi vivenciado por elas e o que versa a literatura sobre os impactos do racismo na vida de pessoas negras. Dessa forma, os relatos apresentaram pontos em comum: vieram de famílias pobres, as agressões seguiam o "ciclo da violência" (fase da lua-de-mel, escalada da tensão, rompimento da violência); sofreram vários tipos de violência doméstica (física, sexual, psicológica etc.); vivenciaram sentimentos constantes de culpa e/ou vergonha pelas agressões sofridas; e todas elas relataram dificuldades em se relacionar amorosamente com outros homens após o rompimento com seu agressor. Também foram relatadas situações nas quais a rede de enfrentamento, responsável por desenvolver condições de prevenção e enfrentamento à violência doméstica, apresentou déficits na execução dessas ações. Por exemplo, Maria (nome fictício), ao prestar queixa por agressão, escutou o quanto ela era uma mulher forte e trabalhadora, que não merecia ser agredida, mas demorou a se separar do marido. A fala fez com que Maria se sentisse com vergonha e humilhada. Maria também relatou que, apesar do pedido de medida protetiva, o agressor não se afastou, mostrando que apenas a medida protetiva não é garantia do fim ou diminuição das agressões.

No geral, os resultados encontrados por Goés (2019) apontaram que os traumas causados pela violência influem negativamente na vida afetiva dessas mulheres, que, apesar de desejarem um relacionamento afetivo, acabam optando pela solidão (esquiva de novos relacionamentos amorosos) para escapar da violência. A rede de enfrentamento 
também necessita de ajustes (e.g. ampliação das ações, treinamento profissional, melhoras na execução etc.) para funcionar mais plenamente.

\section{Sumário quantitativo dos resultados}

Oito trabalhos foram encontrados. Desses, a maioria (três) eram dissertações de mestrado (SOUZA, 2008; FERNANDES, 2018, e GOÉS, 2019). Outros dois trabalhos eram artigos (BARBOSA; SOUZA, 2018; FERREIRA, 2018), dois anais de eventos (CARRERA; CARVALHO, 2019; GREGÓRIO, 2017), e um livro (resultado de uma tese de doutorado - PACHECO, 2013).

A maioria das pesquisas (sete) focou em mulheres negras adultas, enquanto um estudo (BARBOSA; SOUZA, 2018) analisou a solidão em personagens de desenhos infantis, com foco em crianças negras. Todas as pesquisas, com exceção do estudo de Barbosa e Souza (2018), que focou em crianças, eram voltados para relacionamentos entre um homem e uma mulher. Quanto a metodologia dos trabalhos, três utilizaram a pesquisa qualitativa (FERNANDES, 2018; GOÉS, 2019; PACHECO, 2013), outras três utilizaram a pesquisa mista (qualitativa e quantitativa - BARBOSA; SOUZA, 2018; CARRERA; CARVALHO, 2019, e SOUZA, 2008), e duas pesquisas foram teóricas (FERREIRA, 2018, e GREGÓRIO, 2017). Nas pesquisas qualitativas, todas utilizaram a entrevista semiestruturada como forma de obtenção dos dados. A maioria dos trabalhos foi publicada do ano de 2010 à 2019, com uma exceção (SOUZA, 2008 ${ }^{10}$ ), o que mostra que esse tema de pesquisa tem sido uma preocupação recente. Além disso, verificou-se, por meio de heteroatribuição (por uma das autoras deste artigo), que oito das 10 autoras dos trabalhos encontrados são negras, o que mostra que esse tópico tem sido uma preocupação de pesquisadoras negras, e também o protagonismo negro no que se refere a este tema.

\section{DISCUSSÃO}

O objetivo dessa pesquisa foi revisar a literatura, em língua portuguesa, do fenômeno descrito como "solidão da mulher negra", a fim de identificar os possíveis

\footnotetext{
${ }^{10}$ É importante mencionar que o trabalho de Pacheco (2013) foi inicialmente publicado em formato de tese, no ano de 2008.
} 
significados atribuídos a essa terminologia e discutir algumas possíveis causas dessa solidão. Para tanto, três bases de dados foram consultadas, além de uma busca adicional, com o intuito de aumentar o número de trabalhos a serem analisados.

Em todos os trabalhos encontrados, a solidão das mulheres negras tem, prioritariamente, o significado de ausência de parceria afetivo-sexual duradoura, sendo um dado frequente o seu preterimento tanto por homens negros quanto brancos. Esse preterimento é visto como uma das consequências do racismo intersectado ao machismo: o estereótipo de "mulata fogosa" - a visão de que mulheres negras são objetos sexuais, passíveis de desejo sexual, mas não de carinho e amor - utilizado como justificativa para estupros pelos senhores, na época da escravidão, ainda sobrevive no imaginário da população (e.g., BUENO, 2020; COLLINS, 2000; DAVIS, 1981/1983; NASCIMENTO, 2016). Assim, a imagem da mulher negra, permeada pelo racismo e pelo machismo, não corresponde ao ideal de mulher para se ter um relacionamento sério e duradouro, o que pode ser uma das explicações possíveis para o seu preterimento e solidão (e.g. PACHECO, 2013; SOUZA, 2008).

Já para as meninas negras, o racismo também é peça fundamental. Ser considerada feia, suja, ter seus traços fenotípicos desprezados são consequências dos ideais racistas e da ideologia da supremacia branca, onde pessoas da Europa ocidental (origem) e com traços fenotípicos semelhantes a estes (pele branca/clara, olhos claros, cabelo liso) são considerados o padrão e ideal a ser alcançado, enquanto outras origens e padrões fenotípicos são considerados hierarquicamente inferiores aos da brancura (e.g. CARONE; BENTO, 2014; GUIMARÃES, 2009; SOUZA, 1983; SCHWARCZ, 1993). Como resultado, para se encaixar nos padrões de beleza, mulheres negras recorrem frequentemente a procedimentos estéticos (e.g., alisar e/ou tingir o cabelo) na tentativa de acentuar ou extinguir os traços de sua negritude. Por serem características de origem fenotípica, tais traços exigem esforços frequentes e por vezes frustrados de mudança, o que impacta negativamente na autoimagem e autoestima das meninas e mulheres negras (e.g. HOOKS, 1984/2000; SOUZA, 1983). Neste mesmo caminho, podemos derivar que, se i) a beleza física pode estar relacionada às características desejáveis em uma parceira; e ii) o ideal de beleza é relacionado aos traços fenotipicamente semelhantes aos europeus; então iii) quanto mais traços negroides (distantes do ideal de beleza) uma mulher negra 
apresenta, menor a probabilidade de que ela seja considerada bonita/atraente por parceiros amorosos e pela sociedade.

A solidão foi relacionada não apenas à falta de um parceiro (GOÉS, 2019), mas também ao abandono parental (CARRERA; CARVALHO, 2019; FERREIRA, 2018; GREGÓRIO, 2017) ou do próprio parceiro (CARRERA; CARVALHO, 2019; FERREIRA, 2018; SOUZA, 2018), a ausência de interação com outras pessoas negras (BARBOSA; SOUZA, 2018) ou não-negras (GREGÓRIO, 2017), ao preterimento afetivo-sexual (GREGÓRIO, 2017), a ser considerada irrelevante do ponto de vista afetivo (e.g., "não importar para ninguém" - CARRERA; CARVALHO, 2019), e a não se sentir amada (FERNANDES, 2018).

Dentre todos, o preterimento afetivo-sexual obteve destaque nas pesquisas analisadas. Um ponto em comum a diversos trabalhos foi o relato, pelas mulheres negras, de que os homens negros preferem mulheres brancas para relacionamentos afetivosexuais estáveis. Esse relato, algumas vezes, tinham um tom de acusação. Contudo, devese considerar que homens negros também nascem e crescem dentro de uma estrutura racista e machista, de modo que também absorvem os valores de uma sociedade pautada na branquitude e no patriarcado (e.g., ALMEIDA, 2019; AUGUSTINOS; REYNOLDS, 2001; KILOMBA, 2010; SAFFIOTI, 2004/2015; SCHUCMAN, 2014). Como podemos lidar, então, com a queixa legítima das mulheres negras, de que são vistas como objetos sexuais por homens, independentemente de suas raças, e que, quando se voltam para relações afrocentradas, são frequentemente rejeitadas pelos homens negros, que preferem as mulheres brancas, ao mesmo tempo em reconhecemos que estes homens negros também são fruto de uma sociedade racista e machista que os ensina que a brancura é o valor e ideal a ser atingido?

Essa é uma pergunta complexa e que, talvez, mereça um trabalho completo somente sobre esse importante aspecto. No mais, acreditamos ser de extrema importância que aconteça com maior frequência a discussão sobre a influência das práticas racistas nesse caso específico, a reprodução de comportamentos racistas - na escolha de parceiras brancas por homens negros, em detrimento de parceiras também negras. É certo que o machismo funciona como variável importante nessa escolha, apesar disso, é o racismo o fator principal. Por exemplo, a atribuição de rótulos objetificados a mulheres, como "mulher mais valorosa" ou "mulher menos valorosa", é reflexo direto de práticas 
machistas. Entretanto, a definição do que seria uma "mulher mais valorosa" (mulher branca) ou "mulher menos valorosa" (mulher negra) está estritamente relacionada ao racismo. Nesse mesmo sentido, ser a escolha afetivo-sexual de uma mulher branca é sinônimo da existência social (CARNEIRO, 1995), onde o homem negro ascende socialmente, uma vez que a união com mulheres brancas corresponde a absorção dos padrões de branquitude - estética, cultura, prestígio (OLIVEIRA; SANTOS, 2018). Carneiro indica que

neste contexto, a coisificação da mulher branca, além de expressar este novo status, é também um símbolo da aliança com aquele universo branco dominante que produz e reproduz as discriminações e desigualdades raciais e sexuais, tanto no universo concreto como no imaginário (CARNEIRO, 1995, p. 551).

Sendo assim, o racismo aponta como fator central, visto que obriga homens negros à tentativa de elevar seu status social dando prioridade à relacionamentos com mulheres brancas (CARNEIRO, 1995; OLIVEIRA; SANTOS, 2018).

Compreender as questões abordadas acima é imprescindível para que não corramos o risco de culpabilizar os homens de maneira individual, como se estes não fossem parte de uma cultura, o que levaria não só a uma análise relativamente superficial das complexidades envolvendo a raça e o sentimento de solidão, mas também a uma possível divisão entre homens e mulheres negros, que pode dificultar nas lutas antirracistas. Nesse sentido, acreditamos ser importante ampliar o debate, discutindo, por exemplo, a importância de os homens negros entenderem de onde vêm seus gostos e preferências afetivo-sexuais, mas principalmente, entender a influência do racismo e do machismo nessas preferências, e como podemos fazer para reduzi-lo.

Para lidar com a solidão, algumas estratégias foram empregadas, como a adesão a uma religião e a militância negra (e.g., PACHECO, 2013). A militância negra foi particularmente importante, entre outros motivos, por permitir a interação com outras pessoas negras com histórias similares, e também por instrumentalizar essas mulheres em tópicos referentes às relações raciais e também a práticas machistas, comumente reforçadas na vida das mulheres (e.g., "cuidar" do marido, cozinhar e limpar a casa para o marido, não trabalhar fora de casa). 
De modo geral, os resultados mostraram que, desde a infância, as meninas negras vivem em um mundo branco, com escassa representação de si próprias. Conforme nos diz Barbosa e Souza:

Se essas meninas estão sempre sozinhas, como construir sororidade? Como se relacionar para além dos muros individuais? Como erguer pontes entre essas ilhas? Que outros afetos seriam possíveis entre as mulheres negras se o que é oferecido é isolamento? (BARBOSA; SOUZA, 2018, p. 92).

Além de crescerem nesse mundo branco, constituindo uma "ilha", essas crianças crescem sendo expostas e absorvendo diversas imagens que as relacionam com diversos aspectos negativos, como o cuidado dos outros às custas de seu próprio autocuidado, a falta de amor, e a servidão (inclusive sexual - e.g., COLLINS, 2000; DAVIS, 1981/1983). O resultado do entrelaçamento entre uma sociedade racista, machista, classista e cheia de outras desigualdades, é a solidão. Solidão que pode ser vista como o abandono parental; como a morte da cuidadora desta menina/mulher; como a ausência de interação com outras pessoas negras, para compartilhar histórias e promover estratégias de aquilombamento; com a rejeição afetiva; com os parceiros não assumindo publicamente relacionamentos com essas mulheres; com as mulheres negras em situação de prisão abandonadas pelo Estado (pela ausência de políticas públicas efetivas) e separadas de seus filhos e filhas; com o abandono de parceiros para constituir família com mulheres brancas; como sendo maioria representadas sozinhas nos bancos de imagens (CARREIRA; CARVALHO, 2020), mesmo quando a busca é por "família negra"; como a falta de aparatos estatais que deem suporte para mulheres vítimas de violência, com o não-reconhecimento das mulheres negras como seres humanos, dotados de sentimentos e cidadãs com os mesmos direitos que qualquer outra pessoa.

Embora exista a (falsa) concepção de que, no Brasil, existe um modelo harmônico de relações raciais, descrito pelo mito da democracia racial (e.g., NASCIMENTO, 2016), por que é que as mulheres negras são o principal grupo preterido em relações afetivosexuais? ${ }^{11}$ Por que será que mulheres negras são maioria entre as vítimas de violência doméstica? Por que será que são o grupo na base em todos os indicadores sociais? Nas palavras de Pacheco (2013):

\footnotetext{
${ }^{11}$ De acordo com o levantamento mais recente do Censo Demográfico (IBGE, 2010b), o percentual de mulheres casadas, levando em consideração a variável cor, foi de 55,39\% mulheres brancas, 37,18\% mulheres pardas (negras) e 5,84\% mulheres pretas (negras).
} 
Se de fato existe um modelo democrático de relações inter-raciais, como poderia explicar a "solidão" afetiva de mulheres negras (pardas e pretas) no Brasil? Sugiro que raça e gênero, quando combinados, são dois marcadores sociais que afetam mais as mulheres negras do ponto de vista de sua exclusão afetiva-sociocultural do que outros grupos (PACHECO, 2013, p. 51).

\section{Sugestões para estudos futuros}

Sugerimos que estudos futuros ampliem a discussão do preterimento das mulheres negras por homens negros para uma discussão da preferência afetivo-sexual como um tópico social (fortemente influenciado pela cultura), e não individual. Também sugerimos pesquisas que se voltem para a solidão da mulher negra em outras configurações de relacionamentos (e.g. relacionamentos entre mulheres), uma vez que todas as pesquisas revisadas se focaram em relacionamentos entre homens e mulheres. Por fim, sugerimos pesquisas em que a articulação e a importância das variáveis gênero e raça (dentre outras) esteja explícita, uma vez que isso possibilita análises mais completas.

\section{CONSIDERAÇÕES FINAIS}

O presente trabalho revisou a literatura, em língua portuguesa, do fenômeno descrito como solidão da mulher negra. Evidenciou-se que essa solidão tem sido descrita como resultado da ausência de afeto e companhia proveniente de relações afetivas, principalmente em relações afetivo-sexuais. Tal estado de privação está intimamente relacionado aos efeitos de uma cultura racista e machista. Argumenta-se a importância de espaços onde as mulheres negras possam dar vazão aos seus sentimentos e sejam acolhidas e que, ao mesmo tempo, abra-se espaço para a discussão da importância da cultura na preferência afetiva e/ou sexual, de modo a não culpabilizar homens negros individualmente, salientar o papel da cultura na aprendizagem de gostos e preferências, e reduzir um movimento de separação entre homens e mulheres negros, o que enfraqueceria as potencialidades do movimento negro.

\section{REFERÊNCIAS BIBLIOGRÁFICAS}

AKOTIRENE, Carla Santos. Interseccionalidade. São Paulo: Sueli Carneiro; Polén. 2019.

ALMEIDA, Silvio. Racismo estrutural. São Paulo: Pólen, 2019. 
ALVES, Cláudia de Oliveira; MURTA, Sheila Giardini; MOREIRA, Ana Luísa Coelho. "Sobre presença e ausência: revisão de literatura sobre mulheres negras no suas". Revista da Associação Brasileira de Pesquisadores/as Negros/as (ABPN), [S.1.], v. 13, n. 36, p. 601-628, maio 2021.

AUGOUSTINOS, Martha; REYNOLDS, Katherine. Understanding prejudice, racism and social conflict. London: Sage Publications, 2001.

BARBOSA, Karina Gomes; SOUZA, Francielle Neves de. "A solidão das meninas negras: apagamento do racismo e negação de experiências nas representações de animações infantis". Revista ECO-Pós, v. 13, n. 3, p. 75-96, dez. 2018.

BOCK, Ana Maria Bahia. Psicologias: uma introdução ao estudo da Psicologia. São Paulo: Saraiva, 1999.

BRASIL. Art. 59 do Decreto-lei no 3.688/41. Lei das Contravenções Penais. Disponível em $<$ https://www2.camara.leg.br/legin/fed/declei/1940-1949/decreto-lei-3688-3-outubro-1941413573-publicacaooriginal-1-pe.html. Acesso em: 24/02/2021

BUENO, Winnie. Imagens de controle: um conceito do pensamento de Patrícia Hill Collins. Porto Alegre: Zouk, 2020.

CARNEIRO, Sueli. "Gênero, raça e ascensão social". Revista Estudos Feministas, v. 3, n. 2, p. 544-552, jan. 1995.

CARNEIRO, Sueli. Mulheres negras e violência doméstica: decodificando os números. São Paulo: Geledés Instituto da Mulher Negra, 2017.

CARONE, Iray; BENTO, Maria Aparecida Silva. Psicologia social do racismo: Estudos sobre branquitude e branqueamento no Brasil. 6. ed. São Paulo: Vozes, 2014.

CARRERA, Fernanda; CARVALHO, Denise. "Algoritmos racistas: uma análise da hiperritualização da solidão da mulher negra em bancos de imagens digitais". In: ENCONTRO ANUAL DA COMPÓS, PONTIFÍCIA UNIVERSIDADE CATÓLICA DO RIO GRANDE DO SUL, XXVIII, Porto Alegre. Anais... Porto Alegre: Associação Nacional dos Programas de PósGraduação em Comunicação, 2019. p. 1-23.

COLLINS, Patricia Hill. Black feminist thought: knowledge, consciousness, and the politics of empowerment. 2. ed. New York: Routledge, 2000.

CRENSHAW, Kimberle. "Demarginalizing the intersection of race and sex: a black feminist critique of antidiscrimination doctrine, feminist theory, and antiracist politics". University of Chicago Legal Forum, v. 8, n. 1, p. 139-167, 1989.

CRENSHAW, Kimberle. "Documento para o encontro de especialistas em aspectos da discriminação racial relativos ao gênero". Revista de Estudos Feministas, v. 7, n. 12, p. 171-188, jan. 2002.

DAVIS, Angela Yvonne. Women, race \& class. New York: Vintage Books Edition, 1983.

ERIKSON, Erik Homburger. Identidade, juventude e crise. Rio de Janeiro: Zahar, 1972. 
FERREIRA, Lorena Ribeiro. "Engravidei, pari cavalos e aprendi a voar sem asas: Reflexões acerca da afetividade e solidão da mulher negra". Darandina, v. 11, n. 2, p. 1-18, dez. 2018.

FERNANDES, Eliane Gamas. A cor do amor: o racismo nas vivências amorosas de mulheres negras. 2018. Dissertação (Mestrado em Psicologia) - Núcleo da Saúde, Universidade Federal de Rondônia, Porto Velho, RO, Brasil.

GÓES, Eva Dayane Almeida de. Intersecções entre a violência doméstica contra a mulher negra e as configurações afetivas: condicionantes históricos, políticas públicas e impactos sociais no sul da Bahia. 2019. Dissertação (Mestrado em Estado e Sociedade) - Centro de Ciências Humanas e Sociais, Universidade Federal do Sul da Bahia, Porto Seguro, BA, Brasil.

GREGÓRIO, Júlia Fernandes Flauzino. "A solidão da mulher negra encarcerada". In: SEMINÁRIO INTERNACIONAL DE PESQUISA EM PRISÃO. III, Recife. Anais.... Recife. 2017. p. 1-15.

GUIMARÃES, Antônio Sérgio Alfredo. Democracia racial: o ideal, o pacto e o mito. Novos Estudos Cebrap, v. 20, p. 147-162, out. 2001. Disponível em https://www.anpocs.com/index.php/encontros/papers/25-encontro-anual-da-anpocs/st-4/st203/4678-aguimaraes-democracia/file. Acesso em: 24/02/2021.

GUIMARÃES, Antônio Sérgio Alfredo. Racismo e antirracismo no Brasil. 3. ed. São Paulo: Editora 34, 2009.

HASENBALG, Carlos. Discriminação e desigualdades raciais no Brasil. Rio de Janeiro: Graal, 1979.

HASENBALG, Carlos; SILVA, Nelson do Valle. Estrutura social, mobilidade e raça. São Paulo: Vértice, 1988.

hooks, Bell. Feminist theory: from margin to center. Boston, MA: South and Press. 2000.

IBGE - Instituto Brasileiro de Geografia e Estatística. Nupcialidade, fecundidade e migração: resultados da amostra. Rio de Janeiro: IBGE, 2010a. Disponível em $<$ https://biblioteca.ibge.gov.br/visualizacao/periodicos/98/cd_2010_nupcialidade_fecundidade_ migracao_amostra.pdf>. Acesso em: 13/06/2021.

IBGE - Instituto Brasileiro de Geografia e Estatística. Tabela 3193: pessoas de 10 anos ou mais de idade, por estado civil, segundo o estado conjugal, a situação do domicílio, o sexo, a cor ou raça e os grupos de idade. 2010b. Disponível em <https://sidra.ibge.gov.br/tabela/3193\#notastabela>. Acesso em: 13/06/2021.

IBGE - Instituto Brasileiro de Geografia e Estatística. Síntese de Indicadores Sociais: Uma análise das condições de vida da população brasileira. Rio de Janeiro. 2018.

IPEA - Instituto de Pesquisa Econômica Aplicada. Atlas da violência 2019. Fórum Brasileiro de Segurança Pública. Brasília: Rio de Janeiro: São Paulo: Instituto de Pesquisa Econômica Aplicada; Fórum Brasileiro de Segurança Pública, 2019.

KILOMBA, Grada. Plantation Memories: Episodes of everyday racism. 2.ed. Münster: Unrast, 2010. 
MUNANGA, Kabengele. "Uma abordagem conceitual das noções de raça, racismo, identidade e etnia”. In. BRANDÃO, André Augusto P. (Org.). Programa de educação sobre o negro na sociedade brasileira. Rio de Janeiro: EdUFF, 2004. p. 15-34

NASCIMENTO, Abdias. O genocídio do negro brasileiro: processo de um racismo mascarado. 3. ed. São Paulo: Editora Perspectivas, 2016.

NOGUEIRA, Conceição. Interseccionalidade e Psicologia Feminista. Bahia: Devires, 2017.

OLIVEIRA, Ilzver de Matos; SANTOS, Nayara Cristina Santana. "Solidão tem cor? Uma análise sobre a afetividade de mulheres". Interfaces Científicas - Humanas e Sociais, v. 7, n. 2, p. 9-20, out. 2018.

ONU - Organização das Nações Unidas. "Desigualdades raciais no Brasil comprometem oportunidades de trabalho e desenvolvimento humano”. Brasil, 2018.

PACHECO, Ana Cláudia Lemos. Mulher negra: afetividade e solidão. Salvador: EDUFBA, 2013.

SAFFIOTI, Heleieth Iara Bongiovani. Gênero, patriarcado, violência. 2. ed. São Paulo: Expressão Popular, 2015.

SOUZA, Neusa Santos. Tornar-se negro ou as vicissitudes da identidade do negro brasileiro em ascensão social. Rio de Janeiro: Edições Graal, 1983.

SCOTT, Joan. "Gênero: uma categoria útil de análise histórica". Educação e Realidade, v. 16, n. 2, p. 5-22, jul./dez. 1990.

SCHUCMAN, Lia Vainer. "Sim, nós somos racistas: Estudo psicossocial da branquitude paulistana". Psicologia \& Sociedade, v. 26, n. 1, p. 83-94, maio 2014.

SCHWARCZ, Lilia Moritz. O espetáculo das raças: cientistas, instituições e questão racial no Brasil, 1870-1930. São Paulo: Companhia das Letras, 1993.

SCHWARCZ, Lilia Moritz. Nem preto nem branco, muito pelo contrário: cor e raça na sociabilidade brasileira. São Paulo: Claro Enigma, 2012.

SKINNER, Burrhus Frederic. Science and human behavior. New York: Free Press, 1953.

SKINNER, Burrhus Frederic. About Behaviorism. New York: Vintage Books, 1976.

SOUZA, Claudete Alves da Silva. A solidão da mulher negra - sua subjetividade e seu preterimento pelo homem negro na cidade de São Paulo. 2008. Dissertação (Mestrado em Antropologia) - Programa de Estudos dos Pós-graduandos em Ciências Sociais, Pontifícia Universidade Católica de São Paul, São Paulo, SP, Brasil.

TELLES, Edward. Racismo à brasileira: uma nova perspectiva sociológica. Rio de Janeiro: Relume-Dumará/Fundação Ford, 2003.

WENTZEL, Marina. "O que faz o Brasil ter a maior população de domésticas do mundo". $B B C$ News, 2018. Disponível em: 〈https://www.bbc.com/portuguese/brasil-43120953〉. Acesso em: $24 / 02 / 2021$. 
XANGONI, Ana Paula. "Eu tenho pressa". Vídeo do Youtube. 2018. Disponível em: <https://www.youtube.com/watch?v=5fBhjPzXNi4>. Acesso em: 24/02/2021.

As autoras agradecem a Mariana Ribeiro de Castro pela leitura cuidadosa e comentários em uma versão prévia do texto.

Recebido em: 28/04/2021

Aprovado em: 15/09/2021 